\title{
Route of Children with Cancer to the Hematology-Oncology Unit of the Mother and Child Center of the Chantal Biya Foundation
}

\author{
Pondy Ongotsoyi $\mathrm{AH}^{* 1}$, Corbex MA², Djatio Tiogouo NE${ }^{1}$, Wafeu Sadeu G ${ }^{3}$, Molel Belika L ${ }^{4}$, Kenn Chi Ndi ${ }^{5}$, Ngo \\ Nonga $B^{6}$
}

\begin{abstract}
2WHO Regional Office for Europe
${ }^{3}$ Center for développement of Good medical Practice of Yaounde

${ }^{4}$ Départment of anthropology, University of Yaoundé I

${ }^{5}$ Faculties of Medecine and Biomedical Sciences / University of Yaounde

6Faculty of medicine and biomedical sciences, University of Yaounde I
\end{abstract}

${ }^{1}$ Children oncology service, Chantal Biya's foundation/ Pediatrics department, University of Yaounde I

\section{${ }^{*}$ Corresponding Author}

Pondy Ongotsoyi Angèle Hermine

\author{
Article History \\ Received: $\quad 04.09 .2019$ \\ Accepted: 16.09 .2019 \\ Published: 30.09 .2019
}

\begin{abstract}
Purpose: Children with cancer arrive at treatment centers at advanced stages of the disease, with a survival rate of less than $30 \%$. This study analyzes the path of children with cancer to the Hematology-Oncology Department of the Mother and Child Center of the Chantal Biya Foundation in Yaounde. Materials and methods: We conducted a descriptive cross-sectional study from November 2015 to July 2016 including all children aged 0 to 18 years with a confirmed diagnosis of cancer. Data was collected using a questionnaire. Results: We had 155 patients, with a sex ratio of 1.38. The median age was 6 years, with peaks of 2 months and 18 years. The must represented symptoms was fever (29.2\%), followed by abdominal swelling (19.4\%). The median number of resorts before the CME was 3 (2-4) with a minimum of 1 and a maximum of $15.64 .5 \%$ of children were brought to consultation in primary care to a general practitioner. 91 patients had at least three remedies: doctors $(69.5 \%)$, healers and others $(21.8 \%)$. The referral of children was mainly made by a pediatrician (29.5\%). The average time between the onset of symptoms and consultation was 8 months. Patients came mostly at stages 3 and 4 at $51 \%$ and $39.4 \%$, respectively. Conclusion: The majority of patients go to modern medicine. The time of arrival at the Service is long, the stages to the diagnosis very advanced.
\end{abstract}

Keywords: Course - Children - Cancer- Delay- Mother and Child Centre of the Chantal Biya Foundation (MCC-CBF).

\section{INTRODUCTION}

The five-year survival rate for children with cancer has gradually improved in developed countries from $56 \%$ in 1974 to more than $81 \%$ in 2000 in the United States [1, 2]. The considerable improvement in this survival rate can be explained by the early diagnosis and advances in treatment because the prognosis is directly linked to early diagnosis [3, 4].

In sub-Saharan Africa, according to the World Health Organization (WHO), more than 160,000 children are faced with cancer every year, and about 90,000 of them die due to the disease, this prevalence remains underestimated because very few cancers of the children are diagnosed and even followed up in specialized centers [5]. The 5-year survival rate is very low at 20 or even $10 \%$ and the mortality rate is very high at $37.3 \%$ [6]. This death rate is exacerbated by late diagnosis amplified by misdiagnoses $[5,7]$. In Cameroon, the overall finding is the late arrival of patients in the care center. Based on this observation, we therefore proposed to carry out a study on the course taken by children with cancer of the Hematology-oncology Department of the Mother and Child Center of the Chantal Biya Foundation (MCC / CBF).

\section{Materials ANd Methods}

The MCC / CBF hosts on average 130 new cancer cases per year and remains the reference center for the management of childhood cancer in Cameroon. All biological assessments and some routine radiological examinations are free for all hospitalized

Copyright @ 2019: This is an open-access article distributed under the terms of the Creative Commons Attribution license which permits unrestricted use, distribution, and reproduction in any medium for non commercial use (NonCommercial, or CC-BY-NC) provided the original author and source are credited. 
children. The biological examinations are carried out by the Centre Pasteur of Cameroon, standard X-ray, ultrasound and CT are performed in the Radiology Department of the Central Hospital of Yaoundé. Medical treatment of Burkitt lymphoma, Hodgkin's disease, nephroblastoma and standard risk acute leukemia is free.

We carried out a descriptive cross-sectional study from November 2015 to July 2016 in the MCC/FCB Hematology-Oncology department. Included in the study was every child with a confirmed diagnosis of cancer and whose parents had given informed consent to participation. Children hospitalized for cancer relapse were excluded, as were those for whom the diagnosis of cancer had not been confirmed. A questionnaire designed by a WHO expert was filled by the parents, assisted by two student investigators in Psychology. This questionnaire was filled during the first week of hospitalization, even before the diagnosis was made, on suspicion of cancer. The hospital books of each child as well as the medical records of the patients were used to check and complete the information, including clinical and diagnostic.

Our data was recorded using CSPro software version 6.0 and analyzed using IBM SPSS software version 20.0. The qualitative variables were presented with numbers and percentages. Quantitative variables were presented with mean and standard deviation when following the normal distribution or with the median and interquartile range when this was not the case. The data collected in this way has been treated with the utmost confidentiality, in the respect of ethics and professional standards.

\section{RESULTS}

\section{Sociodemographic characteristics}

We included a total of 155 patients, $58 \%$ boys and $42 \%$ girls. The median age was 6 years with the extremes of 2 months and 18 years. Patients from the Central region were 23.9\% compared to $41.9 \%$ from the West region, $250 \mathrm{~km}$ from Yaoundé [Fig. 1]. As for residence at the first symptoms, $39.4 \%$ resided in the Center and $11.0 \%$ in the West and $17.4 \%$ in the Littoral located $240 \mathrm{~km}$ from Yaoundé [Fig. 4]. The most distant regions of the CBF, that is, Yaounde, are the Far North, $1363 \mathrm{~km}$, the North, $1005 \mathrm{~km}$ and Adamaoua, $834 \mathrm{~km}$, with regard to residence at the first symptoms, represented respectively $0.6 \% 1.3 \%$ and $1.9 \%$. The minimum education level of parents in our sample was primary. Secondary education was highest for both fathers and mothers at $45.6 \%$ and $50 \%$, respectively. The highest level of education was $33.9 \%$ for fathers and $20.9 \%$ for mothers.

\section{Clinical features}

The first most represented symptoms [Table I] were 39/155 fever (29.2\%) followed by abdominal swelling 30/155 (19.4\%) and neck mass $18 / 155(11.6 \%)$. The most represented cancers were, in order of frequency [Table II], lymphomas (29\%), followed by leukaemias $(28.4 \%)$ and nephroblastoma (20.6\%) [Fig. 6]. The clinico-biological characteristics [Table III] revealed that the patients surveyed arrived mainly in stage 3 of the disease, ie (51\%) followed by stage 4 , that is $(39.4 \%)$.

\begin{tabular}{|lcc|}
\hline \multicolumn{2}{|c|}{ Table I: Distribution with respect to first symptoms ( $\mathbf{n = 1 5 5 )}$} \\
\hline First Symptom & Number & $\%$ \\
\hline Fever & 39 & 25,2 \\
Abdominal swelling & 30 & 19,4 \\
Neck mass & 18 & 11,6 \\
Tooth ache & 13 & 8,4 \\
Limb pain & 8 & 5,2 \\
Limb swelling & 5 & 3,2 \\
Headache & 3 & 1,9 \\
Swelling of the eye & 3 & 1,9 \\
Movement difficulties & 3 & 1,9 \\
Cat eyes & 2 & 1,3 \\
Weight loss & 2 & 1,3 \\
Others* & 29 & 18,7 \\
* Others: Anemia, abdominal pain, bloody diarrhea, eruptive skin lesions, hematuria, jandice, oral mass, paraly- \\
sis, cough, rectorraghia, jaw swelling,...
\end{tabular}




\begin{tabular}{|c|c|c|c|}
\hline \multicolumn{4}{|c|}{ Table II: Distribution of the first symptoms with respect to the most frequent cancers $(n=155)$} \\
\hline First Symptom & $\begin{array}{l}\text { Lymphoma(n } \\
45)\end{array}$ & $\begin{array}{l}\text { leukemia } \\
(n=44)\end{array}$ & $\begin{array}{l}\text { Nephroblastomal } \\
\text { Wilms tumor } \\
(n=32)\end{array}$ \\
\hline Fever & $10(22.2)$ & $15(34.0)$ & $12(37.5)$ \\
\hline Abdominal swelling & $10(22.2)$ & $5(11.3)$ & $11(34.3)$ \\
\hline Neck mass & $7(15.6)$ & $5(11.3)$ & $2(6.3)$ \\
\hline Tooth ache & $8(17.8)$ & $2(4.2)$ & $0(0)$ \\
\hline Limb pain & $0(0)$ & $3(6.6)$ & $1(3.1)$ \\
\hline Limb swelling & $0(0)$ & $3(6.6)$ & $0(0)$ \\
\hline Headache & $0(0)$ & $3(6.6)$ & $0(0)$ \\
\hline Swelling of the eye & $2(4.4)$ & $1(2.1)$ & $O(0)$ \\
\hline Movement difficulties & $2(4.4)$ & $1(2.1)$ & $0(0)$ \\
\hline Cat eyes & $0(0)$ & $O(0)$ & $0(0)$ \\
\hline Weight loss & $O(0)$ & $1(2.1)$ & $0(0)$ \\
\hline Others* & $6(13.3)$ & $6(13.2)$ & $6(18.8)$ \\
\hline \multicolumn{4}{|c|}{$\begin{array}{l}\text { Table III: Distribution of patients with respect to the clinical-biological staging on entry } \\
(n=155)\end{array}$} \\
\hline Stage at entry & \multicolumn{2}{|c|}{ Number } & Percentage \\
\hline 1 & \multicolumn{2}{|c|}{11} & 7,1 \\
\hline 2 & \multicolumn{2}{|c|}{4} & 2,6 \\
\hline 3 & \multicolumn{2}{|c|}{79} & 51 \\
\hline 4 & \multicolumn{2}{|c|}{61} & 39,4 \\
\hline
\end{tabular}

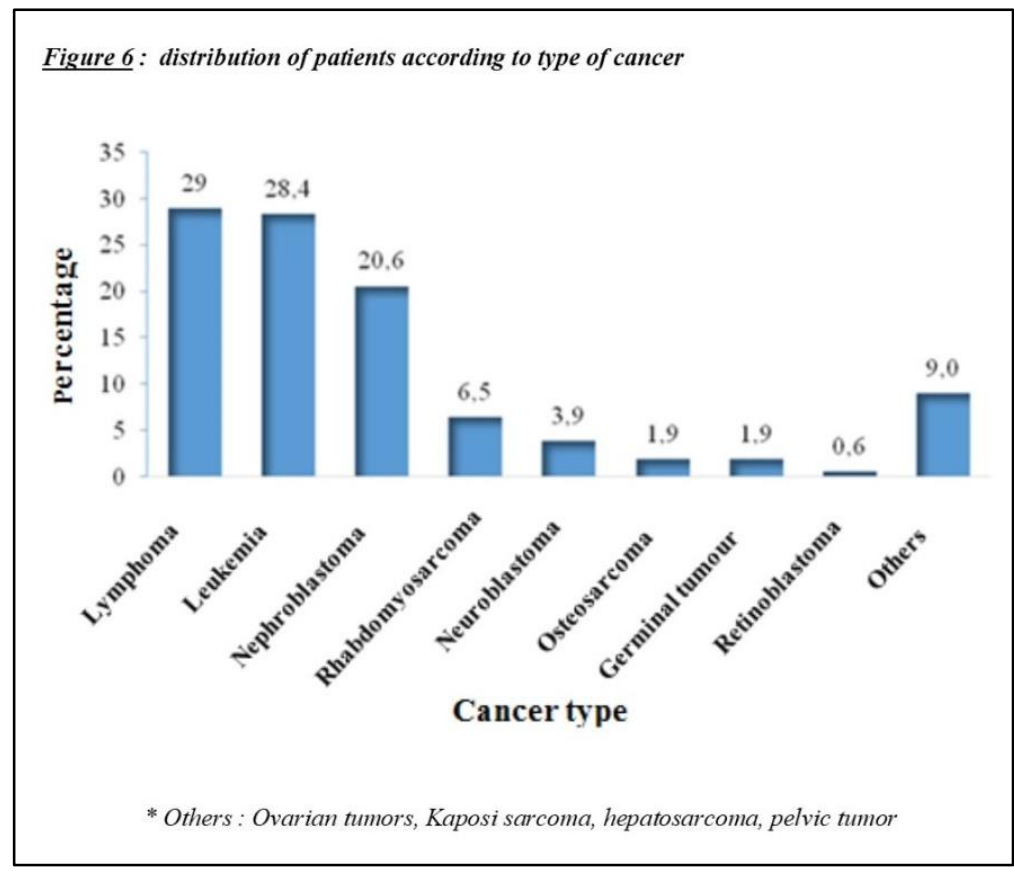

\section{Therapeutic itinerary of patients}

The median number of resorts before the MCC / CBF was $3(2-4)$ with a minimum of 1 and a maximum of 15 [Fig. 5]. In our sample 100/155 (64.5\%) children were brought for first-referral [Fig. 5] to a doctor, and 44/155 (28.4\%) to a nurse. The other health care options were taken by $11 / 155(7 \%)$ of the patients. Consultations in a public institution involved 91 children $(58.7 \%)$. The action taken as a first resort was treatment and assessments for $55 / 155$ (35.4\%) of the patients. After this first resort, 28 patients were referred directly to the CBF.

One hundred and twenty-seven parents had at least two resorts. Of these, $92(72.4 \%)$ consulted a physician, while 15 $(11.8 \%)$ referred to a nurse and $20(15.6 \%)$ referred to healers and other remedies. After this second resort, 36 more patients were referred to the MCC / CBF. 
Ninety-one parents had at least three remedies (59\% of the sample). Of these, $58 / 91(63.7 \%)$ consulted a doctor, $7 / 91$ $(7.6 \%)$ a nurse and $26 / 91(28.4 \%)$ turned to healers and other health options.

In our sample, 50/108 $(46.3 \%)$ of parents consulted their children in first medical consultation with a general practitioner followed by pediatricians $36 / 108$ (33.3\%). The majority of these consultations were in a public institution. The action taken during the first medical consultation was mainly the request for assessment workups 78/108 (47.7\%).

The referral of children to the MCC / CBF was made by a physician different from the physician of first resort at the onset of symptoms in $75 / 155$ (48.4\%) patients. The explanation of the reason for referral was not made to the parents in $98 / 155$ (63, $2 \%$ ) of cases. The reason given to the parents was that they were referred to a hospital where their child could be cured. The diagnosis of cancer was not mentioned in any of the cases.

\section{Evaluation of the different deadlines}

The average time between the first medical visit and the arrival at the MCC was $7.23 \pm 1.2$ months. The delay between arrival at the MCC and transfer to the hematology-oncology department averaged $6.54 \pm 2.1$ days [Table IV]. In total, the mean delay between onset of symptoms and consultation at the MCC hematology-oncology department was $8.3 \pm 1.3$ months [Table V]. The children who arrived at stages 1 and 2 had an average arrival time of 60 and 77 days, respectively, while those diagnosed at stages 3 and 4 arrived at the MCC at the latest, with an average arrival time of 86 respectively and 158 days.

\begin{tabular}{|c|c|c|}
\hline \multicolumn{3}{|c|}{$\begin{array}{c}\text { Table IV: Delay between the onset of symytoms and consultaion at the MCC, with respect to } \\
\text { first health professional met }\end{array}$} \\
\hline First reason for consultation & Average delay in consul- & Standard deviation \\
\hline Healer & 15.5 & 2.1 \\
\hline Pharmacist & 18.7 & 2.2 \\
\hline Nurse & 8.02 & 1.4 \\
\hline General practitioner & 7.7 & 1.2 \\
\hline Pediatrician & 7.2 & 1.1 \\
\hline Surgeon & 10.9 & 2.3 \\
\hline Another doctor & 9.7 & 1.02 \\
\hline
\end{tabular}

\begin{tabular}{|c|c|c|}
\hline \multicolumn{3}{|c|}{$\begin{array}{c}\text { Table V: Delay between the onset of symptoms and consultation at the MCC with respect to } \\
\text { the presenting complaint }\end{array}$} \\
\hline First presenting complaint & delay in consultation (weeks) & $\begin{array}{l}\text { Standard de- } \\
\text { viation }\end{array}$ \\
\hline Fever & 10.09 & 1.8 \\
\hline Abdominal swelling & 7.45 & 1.1 \\
\hline Neck mass & 11.7 & 1.5 \\
\hline Tooth ache & 7.9 & 1.7 \\
\hline Limb pain & 2.9 & 0.3 \\
\hline Limb swelling & 3.8 & 0.5 \\
\hline Headache & 3.4 & 0.4 \\
\hline Swelling of the eye & 10.8 & 0.6 \\
\hline Movement difficulties & 1.8 & 0.1 \\
\hline Cat eyes & 18.8 & 1.1 \\
\hline Weight loss & 5.9 & 0.4 \\
\hline Others* & 7.62 & 0.9 \\
\hline
\end{tabular}

\section{DISCUSSION}

The limitations of this study were that we were not sure that the parents or guardians interviewed were there at the onset of symptoms. Some children who came with their parents did not live with them from the beginning of the illness. And others were rescued from the village by tutors who could not affirm the exact beginning of the disease. In addition, some parents of children interviewed, although present at the onset of symptoms, were reluctant to talk about resorts other than that by health professionals for fear of being stigmatized. The goal of the psychologist in the hematology-oncology department was to strengthen their confidencebuilding. However, the proportion of resort to healers reported here could be underestimated.

\section{Sociodemographic characteristics}

The median age of our study population was 6 years with the extremes of 2 months and 18 years. Our results are similar to those reported by studies in other African countries, including Congo 7.9 years [8] and Nigeria 7.3 years [9]. 
The parents' level of education was higher than primary $82 / 103(79.5 \%)$ for fathers and 78/110 (70.6\%) for mothers. As for the university level, it was $33.9 \%$ for fathers and $20.9 \%$ for mothers. According to UNESCO in Cameroon, the general literacy rate for over-15s in 2010 was $71.29 \%$, with $78.33 \%$ for men and $64.8 \%$ for women [10]. Indeed, the importance of educational achievement has attracted the attention of many other researchers, most of whom have come to the conclusion that the use of healthcare services increases with the educational level of parents. This data is in accord with the choice of parents. In our study population, there was no illiterate, which contrasts with studies done in Cameroon in the far north where the literacy rate is the highest .It is clear from our data that the more a person is educated the more one would expect them to have a more rational perception of the disease, and as a result, to resort systematically to modern medicine, especially in the case of severe illness. Thus, according to Fournier and Haddad, as people go to school, one can expect on the one hand a strengthening of the use of modern health care, on the other hand a reduction of the use traditional medicines [11].

The analysis of the region of origin reveals that children from the West are the majority in the selected sample, ie $41.9 \%$ [Fig. 1]. They are seconded by the natives of the Central region, with $23.9 \%$ of cases. It also appears that patients from the three northern and southwestern regions were the least represented at $5.8 \%$ and $3.2 \%$, respectively. Since the MCC / CBF is the only pediatric cancer center in Cameroon, it is cosmopolitan in that it attracts patients coming from all parts of the country and even from countries in the sub-region.

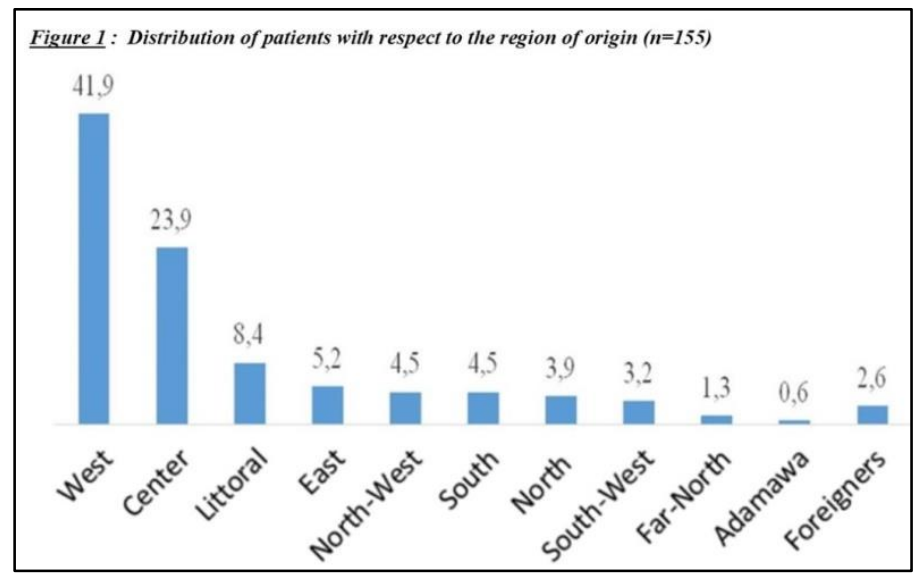

Moreover, when we look at the distribution by region of residence at the beginning of the disease symptoms (Fig 2, Fig 3 and Fig 4), it appears that most of them were in the Center, with a percentage of $39.4 \%$, compared to those in the Far North, $0.6 \%$; Adamaoua, $1.3 \%$ and North $1.9 \%$. This situation can be explained by the fact that the populations of the Center benefit from the proximity of the Mother and Child Center. It goes without saying that the difficulties of access to specialized services for populations in remote areas, particularly nationals of the far north of the country, may explain their low representativeness. This conclusion is similar to that of Fournier and Haddad who showed in their study on the accessibility of patients to health facilities, that the longer the distance, the less sick people are motivated to go to health centers [11].

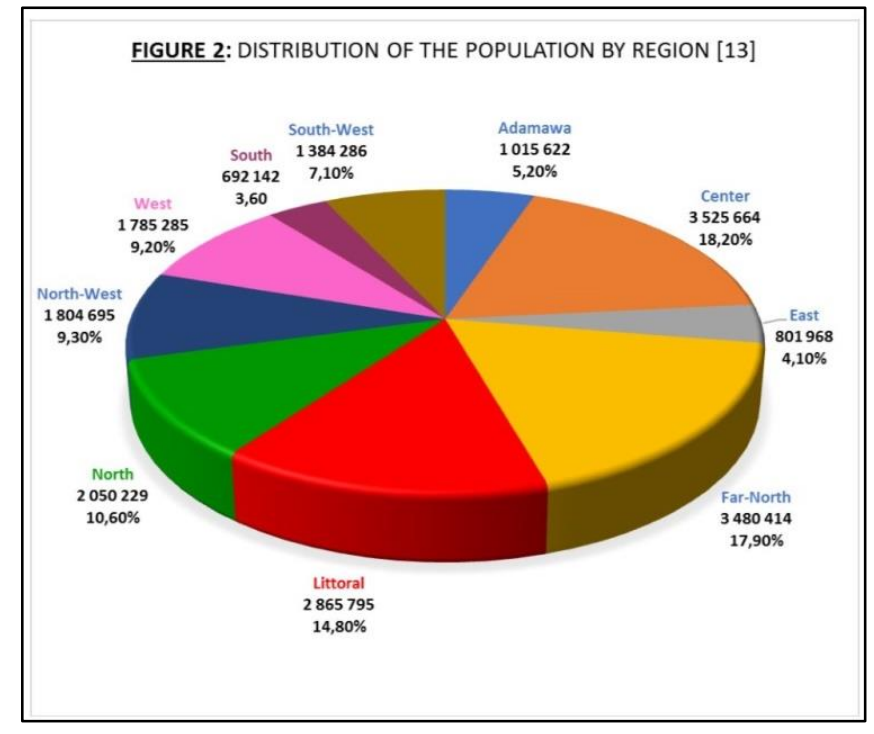



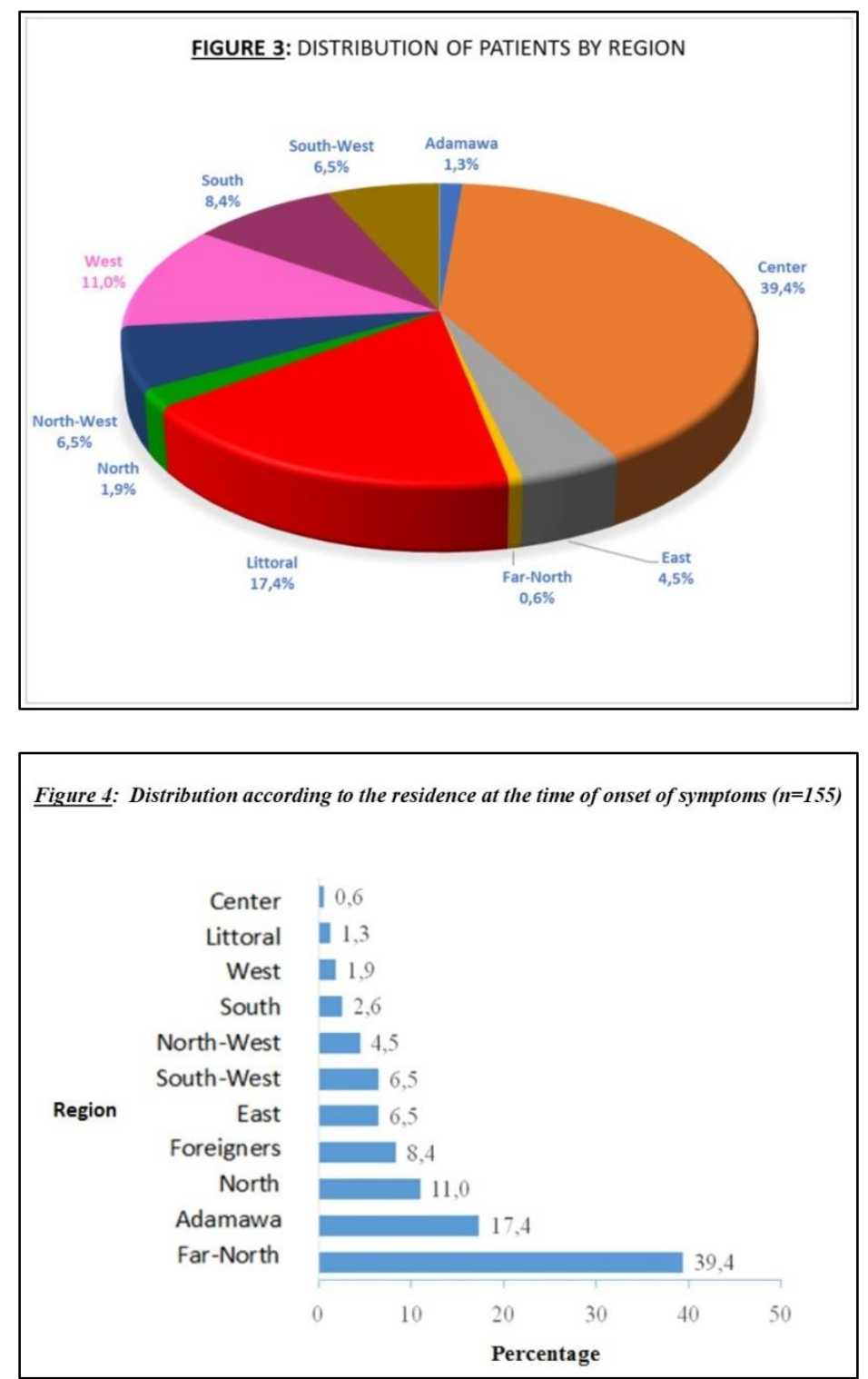

It should be noted that the remoteness of the Far North is not the absolute reason for their under-representation in our sample, given that the regions comprising it, particularly the Far North, the North and Adamawa, are those who have the lowest levels of literacy in the official language (English and French) [12]. Similarly, when comparing the place of residence at the time of the first symptoms and the origin of the children among the residents of the Central Region which is where the MCC is located, children from the Far North are the least represented [Fig. 3].

\section{Clinical features}

In our sample, the most represented symptom was fever $39 / 155(29.2 \%)$. Fever is the response to the release of endogenous pyogenic mediators called cytokines. It is an uncomfortable symptom that causes parents to react. It does not require treatment in otherwise healthy children. The response to antipyretics and the level of temperature do not have a direct relation with etiology or severity. The most common causes of fevers in children being viral, bacterial or parasitic. This symptom is not specific to cancer and is a source of misdiagnosis. Indeed, as several studies show, fever appears among the first major symptoms of several tropical diseases, notably malaria [13] and tuberculosis [14]. For example, children with recurrent or chronic fevers receive multiple treatments for malaria, antibiotics, and TB treatment when they have respiratory signs or lymph nodes. The same is true for swelling of the abdomen $30 / 155(19.4 \%)$ children receive several yeasts and intestinal amoebiases treatment until the mass becomes palpable. The neck mass in 18/155 (11.6\%) children was treated with antibiotic for suspicion of abscess. Whether it is swelling of the abdomen or mass of the neck, their diagnosis requires explorations in medical imaging to determine their exact nature. This is not always accessible, given the insufficient technical facilities in some health structures. Also, the interpretation of radiological images has an operator-dependent character. As tumor pathology in children is rare, it is difficult for an untrained technician to diagnose. 
Analysis of clinical-biological characteristics revealed that the majority of patients arrived at stage 3 of the disease, 79/155 $(51 \%)$ followed by stage 4 , that is $61 / 155(39.4 \%)$ [Table VI]. This observation is similar to the results of the study conducted by Togo $\mathrm{B}$ et al. at Bamako Pediatric Hospital in Mali out of 180 children, according to which the majority of patients had reached stages 3 and 4 in all types of cancer [15]. One study found that in Malawi, which has 6.5 million children under 15, about 900 childhood cancer cases are predictable each year. However, less than 300 cases per year are recorded, which means that two-thirds of children remain undiagnosed, and of the cases diagnosed, the majority are diagnosed at an advanced stage of the disease [16]. The same is true for a study on the state of care in pediatric oncology conducted in Tanzania and Senegal $[17,18]$, childhood cancer is underestimated.

\begin{tabular}{|l|l|l|}
$\begin{array}{l}\text { Table V: Delay between the onset of symptoms and consultation at the MCC with respect to } \\
\text { the presenting complaint }\end{array}$ \\
First presenting complaint & delay in consultation (weeks) & $\begin{array}{l}\text { Standard de- } \\
\text { viation }\end{array}$ \\
\hline Fever & 10.09 & 1.8 \\
Abdominal swelling & 7.45 & 1.1 \\
Neck mass & 11.7 & 1.5 \\
\hline Tooth ache & 7.9 & 1.7 \\
Limb pain & 2.9 & 0.3 \\
Limb swelling & 3.8 & 0.5 \\
Headache & 3.4 & 0.4 \\
Swelling of the eye & 10.8 & 0.6 \\
Movement difficulties & 1.8 & 0.1 \\
Cat eyes & 18.8 & 1.1 \\
Weight loss & 5.9 & 0.4 \\
Others* & 7.62 & 0.9 \\
\hline
\end{tabular}

Moreover, as the literature reveals, the difficulty of late diagnosis of childhood cancer is common to many African countries. We can assume that this arrival at advanced stages might find one of its justifications in the misdiagnosis arising from the nonspecificity of the symptoms. Yet, in developed countries, early diagnosis has become a reality and has clearly helped improve child survival over the last twenty years [19, 20].

\section{Patient journey before arrival at the MCC}

The majority of our patients went directly to modern health facilities: 100/155 (64.5\%) first met a doctor; $44 / 155$ (28.4\%) a nurse; and only 11/155 (7\%) of patients consulted as first option other care trajectories such as traditional healers, churches and street drug dealers.

These results show the high frequency of consultations in health facilities, including general practitioners, the first point of contact with the health care system [Table IV]. In doing so, they differ from the conclusions of the study conducted by Commeyras et al. [21] who had highlighted the indecision characterizing the therapeutic behavior of Cameroonian patients. Thus, according to him, the consultation as first option in a health facility is very weak $(24 \%)$. This difference in data is related to the fact that our work is done on a specific sample consisting of children who have symptoms that have a serious potential such as fever, pain resulting in resorts to health facilities that are able to calm these signs or symptoms quickly [Table V]. Moreover, from a socio-cultural point of view, these signs are related to pathologies known as "hospital diseases" [22].

Moreover, without negating the findings of Commeyras who have based on the general population taking into account all pathologies, in view of our results, we can conclude that in the first resort, despite the influence of parallel medicine, the majority of parents of patients do not question the effectiveness of modern medicine.

When we look at the trajectory followed by our second-line patients, one constant remains: doctors are still mainly resorted to by parents of children, that is $92 / 127(72.4 \%)$ of cases [Fig. 5]. Nurses are the second most frequent resorts, accounting for $15 / 127$ $(11.8 \%)$ of the visits. On the other hand, resorts to alternative care-givers (healers, street medicine and church vendors) have increased from $7 \%$ to $15.6 \%$. Indeed, as in the study by Commeyras et al. [19], the therapeutic routes are very variable and most of the patients change from one healthcare sector to another. 
Figure 5: Therapeutic itenary of our patients

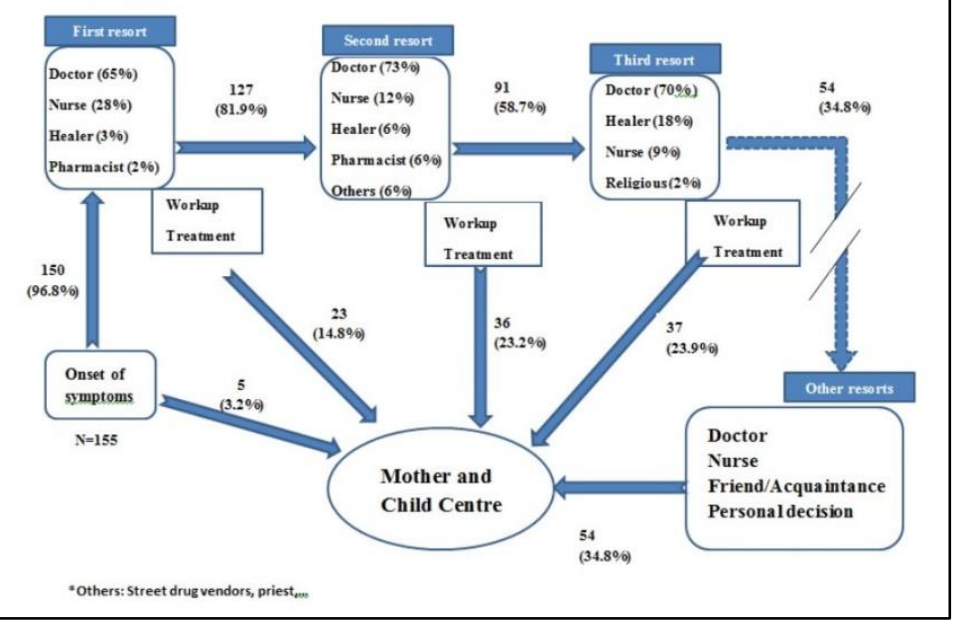

This finding was also found in the study by Diop who found a $35.8 \%$ increase in second-line treatment in epileptic patients [17]. As a third resort, it appears that general practitioners are always the first to be consulted: $58 / 91$ (63.7\%) while nurses register $7 / 91(7.6 \%)$. Indeed, all specialists agree that the general practitioner has his place throughout the care of a cancer patient by his presence during screening and diagnosis. In addition, the other health services mentioned above continue to welcome new patients who have abandoned public health facilities $26 / 91(28.4 \%)$. This willingness to turn to alternative medicine is well recounted by the cured patients who testify: faced with the persistence of the symptoms, after a certain number of consultations, we went (I use their words) to shield the child or to work on the child. This shielding or working on the child aims either to cure or to make the disease come out and become visible to modern medicine. Thus, it could be said that it is the absence of satisfactory responses from caregivers or the etiological beliefs of cancer populations that lead parents to alternative medicine.

From this study, the average time between onset of symptoms and consultation at the MCC hematology-oncology department was $8.3 \pm 1.3$ months. A similar result is found in Bamako in the work of Togo $B$ et al. on the prognosis of pediatric cancers at CHU Gabriel-Touré [15]. These Malian researchers found an average consultation time of 6 months. The association between stage at diagnosis and time to arrive at MCC /CBF shows that children who arrived at stages 1 and 2 had an average arrival time of 60 and 77 days respectively, while those diagnosed at 3 and 4 had an average delay of 86 and 158 days, respectively, with a statistically significant link between the arrival time and the stage of the disease $(P=0.04)$. This data shows that early diagnosis would improve prognosis by increasing the number of stages 1 and 2 , and decrease stages 3 and 4 at diagnosis. Diagnostic delays resulting in lateness in the arrival at specialized services. In the health system in Cameroon this lateness could be attributed to: 1) health facilities that do not allow patients to often see the doctor who consulted them, with each new consultation. 2) there is no communication between the health facilities, and the referral and counter referral system is not applied. 3) Families who have nonbiomedical ideologies of the disease often use other therapies. Moreover, we can link this lateness to the lack of training of the caregivers who do not have the ability to suspect cancerous conditions in children.

\section{CONCLUSION}

Most children had at least three resorts before they arrived at the MCC / CBF. These remedies were preferentially directed to modern medicine, specifically to the general practitioner. Some resorted to traditional healers, churches and street vendors, among others. The western and central regions were the most represented. The most common symptoms were fever, swelling of the abdomen and neck mass. The most common tumors were lymphoma, leukemia and nephroblastoma. Stages 3 and 4 were the most frequent, with a mean delay between onset of symptoms and arrival at the CME of 8 months. Moreover, patients' therapeutic behavior is dependent on individual characteristics reinforced by the socio-cultural context of poverty, education and place of residence. Patients adapt their therapeutic route primarily to their financial means, their geographical access to health facilities and finally to their socio-cultural perception of the disease. Therefore, to reduce as much as possible the influence of these determinants in a better management of childhood cancers, we recommend an awareness of the health staff in the early diagnosis of childhood cancers.

\section{REFERENCES}

1. Siegel, R. L., Miller, K. D., \& Jemal, A. (2016). Cancer statistics, 2016. CA: a cancer journal for clinicians, 66(1), 7-30.

2. Clavel, J., Goubin, A., Auclerc, M. F., Auvrignon, A., Waterkeyn, C., Patte, C., ... \& Sommelet, D. (2004). Incidence of childhood leukaemia and non-Hodgkin's lymphoma in France: National Registry of Childhood Leukaemia and Lymphoma, 19901999. European journal of cancer prevention, 13(2), 97-103. 
3. Parkin, D.M. (2002). Cancer in 5 continents Vol. VIII. IARC Scientific Publications, 155: 87-101.

4. Linet, M. S., Ries, L. A., Smith, M. A., Tarone, R. E., \& Devesa, S. S. (1999). Cancer surveillance series: recent trends in childhood cancer incidence and mortality in the United States. Journal of the National Cancer Institute, 91(12), 1051-1058.

5. OMS. (2013). Statistiques sanitaires mondiales, Genève, Organisation mondiale de la santé.

6. UNICEF, Statistiques. UNICEF.(2015). [Récupéré le 16 décembre 2018] Disponible: https://www.unicef.org/french/infobycountry/cameroon_statistics.html.

7. Tchemtchoua, Youta, J. (2003). Cancers de l'enfant au Cameroun: Etude de la morbi-mortalité au Centre Mère et Enfant de 2003 à 2008, Thèse Med : Université de Yaoundé I, FMSB, 2008.

8. Divino, J.J. (2007). Mon enfant, ma bataille : 26 programmes lancés dans 16 pays pour lutter contre les cancers de l'enfant, Global cancer control.

9. Plantaz, D. (2003). Particularités épidémiologiques des cancers chez l'enfant (144a). InCorpus Médical - Faculté de Médecine de Grenoble, 2003 (mise à jour mai 2005).

10. Cussó, R. (2003). Les statistiques de l'éducation de l'UNESCO: restructuration et changement politique. Education et sociétés, (2), $57-72$.

11. Brugieres, L., Rodary, C et Clavel, J. (2008). Epidémiologie des cancers de l'enfant. Cancers de l'enfant, Paris, Flammarion, 313.

12. Peko, J. F., Moyen, G., \& Gombe-Mbalawa, C. (2004). Les tumeurs solides malignes de l'enfant à Brazzaville. Aspects épidémiologiques et anatomo-pathologiques. Bull Soc PatholExot. 97: 2,117-188.

13. Brown, B.J., Bamgboye, E.A., Sodeinole, O. (2008). Causes of death in childhood cancer at the department of paediatrics, university college hospital Ibadan, Nigeria. Afr J. Med Sci. Mar; 37(1): 7-13.

14. BUCREP, 3ème RGPH. (2019). Scolarisation - Instruction - Alphabétisation. [Récupéré le 16 février 2019] Disponible: http://www.bucrep.cm/index.php/.

15. Fournier, P et Haddad, S. (1995). Les facteurs associés à l'utilisation des services de santé dans les pays en développement. In Gérard H. La sociologie des populations, Montréal, AUPELF/UREF, 289-325.

16. Etat et structures de la population : indicateurs démographiques. September. 2010 BUCREP. [Récupéré le 17 janvier 2019]. Disponible : http://www.bucrep.cm/index.php/fr/component/phocadownload/category/20-prsentation-des-rsultats.

17. Julie Porcher $z$. Évaluation de facteurs cliniques prédictifs de pyélonéphrite aigüe aux urgences pédiatriques chez les nourrissons fébriles de 3 à 24 mois. Médecine humaine et pathologie. 2015. <dumas-01232142>

18. Delley-Michel, V. (1998). Approche épidémiologique du paludisme en zone d'endémie : incidence de fièvre chez les enfants de 1 à 12 ans et suivi de variations naturelles de la parasitémie chez les adultes, Thèse Med: Université de Genève.

19. Tattevin, P. (2008). Etude du délai diagnostique et de ses déterminants au cours de la tuberculose-maladie en France, [En ligne] 2008 [Récupéré le 2 août 2016]. Disponible : http://www.infectiologie.com/UserFiles/File/medias/JNI/JNI11/CL/JNI2011-delai-bkTattevin.pdf.

20. Togo, B. (2014). Épidémiologie et pronostic des cancers pédiatriques au CHU Gabriel-Touré de Bamako (Mali), Médecine et Santé Tropicales. 24, n 1, Janvier-Février-Mars 2014.

21. Gray, Kanteng, A Wakamb. (2013). Problématique de la prise en charge du cancer de l'enfant: expérience du rétinoblastome à Lubumbashi (RD Congo) et importance du diagnostic précoce, PanAfricanMedical Journal, 14: 64. Disponible: http://www.ncbi.nlm.nih.gov/pmc/articles/PMC3617604/

22. Diop, T. (2001). Itinéraire thérapeutique des épileptiques fréquentant le service de neurologie du CHU de Fann, Thèse Med : Université Cheikh AntaDiop,

23. Ribeiro, R.C., Steliarova-Foucher, E., Magrath, I., Lemerle, J., Eden, T., Forget, C., Mortara, I., Tabah-Fisch, I., Divino, J.J., Miklavec, T., Howard, S.C.(2008). Baseline status of paediatric oncology care in ten low-income or mid-income countries receiving My Child Matters support: a descriptive study. The lancet oncology, 1;9(8):721-9.

24. INSERM, Expertise collective. (2005). Cancers: pronostics à long terme, 225-269.

25. Lynet, M.S. (1999). Cancer surveillance series: recents trends in childhood cancer incidence and mortality in the United States, Journal of the National Cancer Institute june, 92, $n^{\circ} 12$.

26. Commeyras, C. (2006). Comportement de recours aux soins et aux médicaments au Cameroun, Cahiers Santé, (16), n $1: 1-12$.

\section{Contributions des auteurs}

Conception et design : Pondy Ongotsoyi Angèle Hermine, Corbex Marilys Anne

Échantillonnage : Pondy Ongotsoyi Angèle Hermine, Djatio Tiogouo N. Emeline

Collecte et assemblage de données: Pondy Ongotsoyi Angèle Hermine, Djatio Tiogouo N. Emeline

Analyse et interpretation des données: Pondy Ongotsoyi Angèle Hermine, Corbex Marilys Anne, Djatio Tiogouo N. Emeline, Wafeu Sadeu G., Molel Belika Léopold

Rédaction du manuscrit: tous les auteurs

Approbation finale du manuscrit: tous les auteurs

Déclaration de liens d'intérêts

Les auteurs déclarent ne pas avoir de liens d'intérêts. 